\title{
Liver fat content and lipid metabolism in dairy cows during early lactation and during a mid-lactation feed restriction
}

\author{
J. J. Gross, ${ }^{*}$ F. J. Schwarz,† K. Eder,† H. A. van Dorland, ${ }^{*}$ and R. M. Bruckmaier ${ }^{* 1}$ \\ *Veterinary Physiology, Vetsuisse Faculty, University of Bern, Bremgartenstr. 109a, CH-3001 Bern, Switzerland \\ †Department of Animal Sciences, Chair of Animal Nutrition, Technical University of Munich, Liesel-Beckmann-Str. 6, \\ D-85350 Freising-Weihenstephan, Germany \\ ‡Institute of Animal Nutrition and Nutrition Physiology, Justus-Liebig-Universität Giessen, Heinrich-Buff-Ring 26-32, D-35392 Giessen, Germany
}

\begin{abstract}
During the transition period, the lipid metabolism of dairy cows is markedly affected by energy status. Fatty liver is one of the main health disorders after parturition. The aim of this study was to evaluate the effects of a negative energy balance (NEB) at 2 stages in lactation [NEB at the onset of lactation postpartum (p.p.) and a deliberately induced NEB by feed restriction near $100 \mathrm{~d}$ in milk] on liver triglyceride content and parameters of lipid metabolism in plasma and liver based on mRNA abundance of associated genes. Fifty multiparous dairy cows were studied from wk 3 antepartum to approximately wk 17 p.p. in 2 periods. According to their energy balance in period 1 (parturition to wk 12 p.p.), cows were allocated to a control (CON; $\mathrm{n}=25$ ) or a restriction group (RES; $70 \%$ of energy requirements; $\mathrm{n}=25$ ) for $3 \mathrm{wk}$ in mid lactation starting at around $100 \mathrm{~d}$ in milk (period 2). Liver triglyceride (TG) content, plasma nonesterified fatty acids (NEFA), and $\beta$-hydroxybutyrate were highest in wk 1 p.p. and decreased thereafter. During period 2, feed restriction did not affect liver TG and $\beta$-hydroxybutyrate concentration, whereas NEFA concentration was increased in RES cows as compared with CON cows. Hepatic mRNA abundances of tumor necrosis factor $\alpha$, ATP citrate lyase, mitochondrial glycerol-3-phosphate acyltransferase, and glycerol-3-phosphate dehydrogenase 2 were not altered by lactational and energy status during both experimental periods. The expression of fatty acid synthase was higher in period 2 compared with period 1, but did not differ between RES and CON groups. The mRNA abundance of acetyl-coenzyme Acarboxylase showed a tendency toward higher expression during period 2 compared with period 1 . The solute carrier family 27 (fatty acid transporter), member 1 (SLC27A1) was upregulated in wk 1 p.p. and also during feed restriction in RES cows. In conclusion, the
\end{abstract}

Received October 9, 2012.

Accepted April 30, 2013.

${ }^{1}$ Corresponding author: rupert.bruckmaier@vetsuisse.unibe.ch present study shows that a NEB has different effects on hepatic lipid metabolism and TG concentration in the liver of dairy cows at early and later lactation. Therefore, the homeorhetic adaptations during the periparturient period trigger excessive responses in metabolism, whereas during the homeostatic control of endocrine and metabolic systems after established lactation, as during the period of feed restriction in the present study, organs are well adapted to metabolic and environmental changes.

Key words: fatty liver, lipid metabolism, negative energy balance, dairy cow

\section{INTRODUCTION}

Etiology and occurrence of fatty liver, representing a serious metabolic disorder in periparturient dairy cows, have been demonstrated frequently over the past years (Grummer, 1993; Bobe et al., 2004). The first weeks of lactation in dairy cows are shaped by a negative energy balance (NEB) in consequence of a delayed increase in feed intake (Rukkwamsuk et al., 1999). Besides endocrine and metabolic changes, physiological status and level of production affect metabolic turnover and nutrient fluxes between different tissues (Bauman and Currie, 1980; Drackley et al., 2006). In this respect, during the transition from late gestation to early lactation, considerable amounts of adipose tissue are mobilized, resulting in elevated plasma NEFA to support increased energy requirements in dairy cows.

Circulating NEFA can be oxidized in the hepatocytes or exported as constituents of very low density lipoproteins (VLDL; Brickner et al., 2009). However, postpartum release of NEFA from adipose tissue mostly exceeds the needs and oxidation capabilities of the liver (McNamara, 2000) and causes formation of ketone bodies (e.g., BHBA) and reesterification to triglycerides (TG; Grummer, 1993; Brickner et al., 2009). The latter are stored in hepatocytes and implicate the development of fatty liver (Grummer, 1993). Depending on the degree of histological and compositional changes, the incidence of fatty liver is associated with reduced meta- 
bolic function, health status, production, and reproductive performance, as well as incidence and severity of metabolic disorders and infectious diseases (Veenhuizen et al., 1991; Bobe et al., 2004).

Previously, we have reported different effects of a NEB at 2 stages in lactation (NEB in early lactation and a deliberately induced NEB by feed restriction at 100 DIM) on performance parameters and metabolites in dairy cows (Gross et al., 2011a). Even though the extent of the induced NEB in established lactation was higher compared with the NEB in early lactation, observed changes in plasma metabolites during the deliberately induced NEB were less pronounced than during the NEB in early lactation. In further analyses, the underlying endocrine alterations accounting for mobilization of body reserves were studied, focusing the somatotropic axis and related compounds (Gross et al., 2011b). In the present study, attention was turned to the liver TG content and the regulation of hepatic lipid metabolism predominantly based on mRNA expression of enzymes during these 2 periods of an energy deficiency. The hypothesis was tested that the hepatic adaptation to NEB at parturition and to a deliberately induced NEB by feed restriction at 100 DIM is differently regulated.

\section{MATERIALS AND METHODS}

\section{Experimental Study}

The animal study was conducted at the Agricultural Experimental Unit Hirschau of the Technical University of Munich (Germany) and was approved by the Bavarian State Animal Care and Use Committee. The study included 50 multiparous Holstein dairy cows (3.2 \pm 0.2 parities; mean \pm SEM) and covered the period from wk 3 antepartum (a.p.) to approximately wk 17 postpartum (p.p.) in 2 experimental periods. Cows were not inseminated throughout the entire study.

In experimental period 1 (wk 3 a.p. to 12 p.p.), all cows were treated similarly. In experimental period 2 at $98 \pm 7$ DIM, animals were allocated equally to either a control (CON) or a restriction (RES) group. Each group consisted of 25 cows, and the feed restriction (period 2) lasted for $3 \mathrm{wk}$. The week before feed restriction was designated as wk 0 , where all cows were not subjected to a treatment. Procedures and the feeding regimen were recently described in more detail (Gross et al., 2011a).

\section{Determination of Energy Balance}

Energy balance was calculated for each individual cow once per week by subtracting energy requirements for maintenance and milk production from energy intake via feed. More details on determination of energy content of feed and milk were reported previously (Gross et al., 2011a).

\section{Blood Collection and Analyses of Metabolites}

Blood samples obtained via jugular vein puncture between 0730 and $0900 \mathrm{~h}$ before feeding in wk 3 a.p. and wk 1 and 4 p.p. (period 1), and during period 2 in wk 0 and 3 were immediately cooled down on wet ice and centrifuged for $15 \mathrm{~min}$ at $2,000 \times \mathrm{g}$. Aliquots $(1$ $\mathrm{mL}$ ) of plasma were stored at $-20^{\circ} \mathrm{C}$ until analysis of metabolites.

Concentration of plasma NEFA and BHBA were measured enzymatically using kit no. FA 115 and RB 1007 from Randox Laboratories Ltd. (Schwyz, Switzerland). The method of BHBA measurement was based on the oxidation of D-3-hydroxybutyrate to acetoacetate by the enzyme 3-hydroxybutyrate dehydrogenase, where concomitantly NAD+ is reduced to NADH, and changes of absorbance were measured at $340 \mathrm{~nm}$. Nonesterified FA were detected by colorimetric measurement at $550 \mathrm{~nm}$ after enzymatic incubation with acyl-CoA-synthetase, acyl-CoA-oxidase, and peroxidase.

\section{Liver Tissue Collection, Triglyceride Determination, mRNA Extraction, and Quantitative Real-Time Reverse-Transcription PCR}

Liver samples were obtained by blind percutaneous needle biopsy $(14 \mathrm{G} \times 152 \mathrm{~mm}$; Dispomed Witt oHG, Gelnhausen, Germany) under local anesthesia after blood sampling as previously performed in Gross et al. (2011b) at wk 3 a.p. and wk 1 and 4 p.p., and before feed restriction in wk 0 and 3 of period 2. An aliquot $(\sim 40 \mathrm{mg})$ of the liver tissue was frozen immediately at $-20^{\circ} \mathrm{C}$ until determination of TG content. Liver TG content was measured after extraction according to Schlegel et al. (2012). In brief, lipids from biopsy tissue were extracted with a mixture of n-hexane and isopropanol $(3: 2, \mathrm{vol} / \mathrm{vol})$. An aliquot of the extracts containing 25 to $50 \mathrm{nmol}$ of TG was transferred into a glass vial $(1.5 \mathrm{~mL})$. After evaporation of the solvent by vacuum, the lipids were resolved in a $20-\mu \mathrm{L}$ portion of a 1:1-mixture of chloroform and Triton X-100, and the solvent was evaporated again. The TG content was measured by colorimetry using a commercially available enzymatic TG kit (Fluitest TG; Analyticon Biotechnologies AG, Lichtenfels, Germany). Lipoprotein lipase hydrolyzes TG to glycerol, which is followed by oxidation to dihydroxyacetone phosphate and hydrogen peroxide. The hydrogen peroxide produced then reacts with 4-aminophenazone and 4-chlorophenol under the 
catalytic action of peroxidase to form a red dyestuff whose absorbance is measured at $550 \mathrm{~nm}$.

After liver biopsies, additional liver tissue (40 to 60 $\mathrm{mg}$ ) was directly put into an RNA stabilization reagent (RNAlater; Ambion, Applied Biosystems Business, Austin, TX), and kept at $+4^{\circ} \mathrm{C}$ for $24 \mathrm{~h}$, and thereafter stored at $-20^{\circ} \mathrm{C}$ until analyzed. Total RNA was isolated from liver tissue using the peqGOLD TriFast isolation system (Peqlab Biotechnologie GmbH, Erlangen, Germany) according to the manufacturer`s instructions. The yield and purity of total RNA were detected by spectrophotometer with a BioPhotometer (VaudauxEppendorf, Basel, Switzerland). The RNA integrity was verified by the optical density (OD) at 260-nm wavelength:OD at $280-\mathrm{nm}$ wavelength $\left(\mathrm{OD}_{260}: \mathrm{OD}_{280}\right)$ absorption ratio, which was between 1.7 and 2.1 for all samples.

Details on the reverse transcription of extracted total RNA and subsequent PCR quantification were described in Gross et al. (2011b). The genes selected to measure the expression from key enzymes and parameters of the hepatic lipid metabolism are shown in Table 1.

\section{Statistical Analysis}

Data presented in the text and figures are means \pm standard error of the mean. To identify changes over time within groups, data on energy balance, plasma metabolites, and mRNA abundance (delta cycle threshold, $\left.\log _{2}\right)$ at the respective time points of liver biopsies and blood samples in period 1 (wk 3 a.p. and wk 1 and 4 p.p.) and period 2 (wk 0 and 3) were evaluated by a MIXED model in SAS (version 9.2; SAS Institute Inc.,
Cary, NC), with time point and parity as fixed effects. Differences over time were detected by the Bonferroni $t$-test.

To evaluate the effect of feed restriction (period 2) on energy balance, plasma metabolites, and gene expression in liver, data in wk 3 of period 2 was evaluated in a MIXED model, including group and parity as fixed effects. Furthermore, the results of wk 0 in period 2 were used as a co-variable and individual cow as repeated subject. Group differences were detected by the Bonferroni $t$-test. Relationships between liver TG and energy balance, metabolites and hepatic mRNA abundance of lipid metabolism-related parameters were evaluated by linear regression models using PROC REG of SAS; $P$ values $<0.05$ were considered to be significant.

\section{RESULTS}

\section{Energy Balance During the Experimental Stages}

Energy balance (EB) changed during lactational stage and in response to experimental treatment of cows. Weekly data on EB were shown previously in Gross et al. (2011a). The EB dropped from a positive value in wk 3 a.p. to a nadir in wk 1 p.p. for CON and RES groups (Table 2). This lactational NEB decreased in wk 4 p.p. and was positive again at the beginning of period 2 (wk 0) for both groups. From wk 0 to 3 of the feed-restriction period (period 2), the EB decreased in RES cows $(P<0.05)$, whereas the EB for CON cows remained unchanged. The EB was lower for RES cows in wk 3 of period 2 compared with wk 1 p.p. In wk 3 of period 2, the EB was lower in the RES group than in the CON group $(P<0.05$; Table 2$)$.

Table 1. Polymerase chain reaction primer information, the annealing temperature, and the PCR product length for the genes analyzed in liver samples

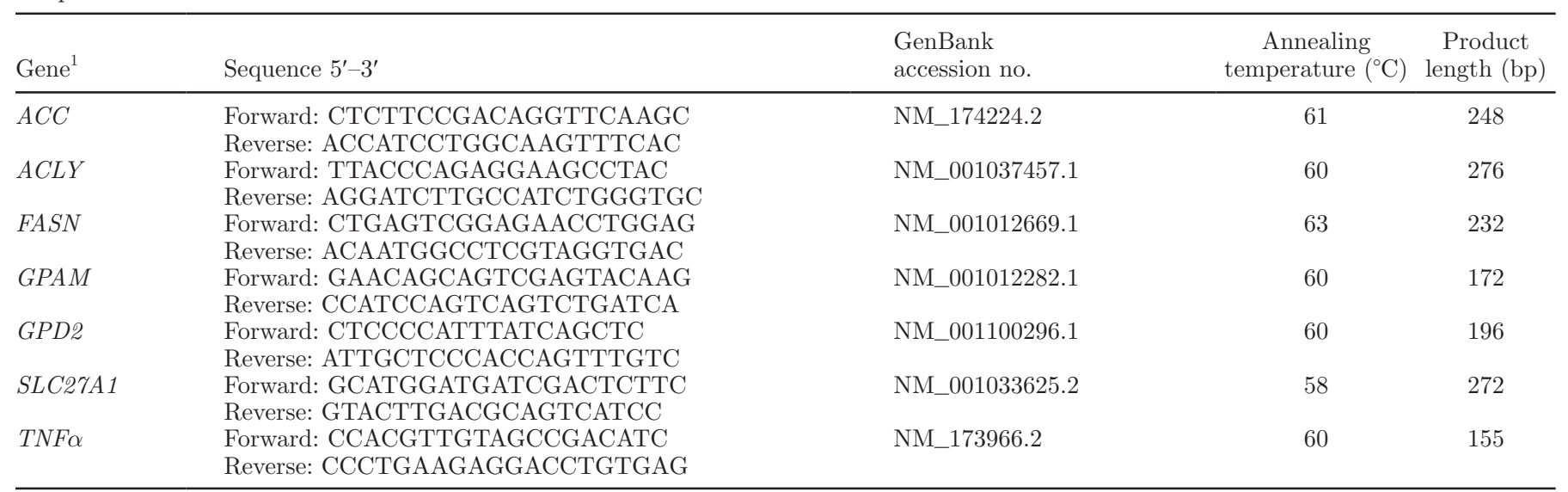

${ }^{1} A C C=$ acetyl-CoA-carboxylase $\alpha ; A C L Y=$ ATP citrate lyase; $F A S N=$ FA synthase; $G P A M=$ glycerol-3-phosphate acyltransferase, mitochondrial; GPD2 = glycerol-3-phosphate dehydrogenase 2, mitochondrial; SLC27A1 = solute carrier family 27 (FA transporter), member 1; TNF $\alpha$ $=$ tumor necrosis factor $\alpha$. 


\section{Plasma NEFA and BHBA Concentrations}

Weekly results on plasma NEFA and BHBA profiles were described earlier (Gross et al., 2011a). Creating a basis for discussion, results of NEFA and BHBA corresponding to new findings here are picked up in brief for the respective time points of sampling. Plasma concentration of NEFA increased from wk 3 a.p. up to a maximum in wk 1 p.p. and decreased thereafter until wk 0 of period 2 for both groups (Table 2). Nonesterified FA concentration did not increase for CON cows, whereas NEFA concentration increased for RES cows during the feed-restriction period $(P<0.05$; Table 2$)$. The NEFA concentration in wk 3 of period 2 was lower compared with wk 1 p.p. in RES cows $(P<0.05)$. At the end of the feed-restriction period, RES cows had a higher plasma NEFA concentration compared with CON cows $(P<0.05)$.

From wk 3 a.p. to 1 p.p., plasma BHBA concentration increased and decreased afterward until the beginning of period 2 for both groups (Table 2). For CON and RES cows, plasma BHBA concentration did not change during period 2. Comparing wk 1 p.p. and wk 3 of period 2 for RES cows, BHBA concentration was not different. In wk 3 of period 2, the BHBA concentration was not affected by feed restriction.

\section{Liver TG Content}

Liver TG content increased transiently from late gestation (wk 3 a.p.) to a maximum in wk 1 p.p. $(P$ $<0.05)$ and decreased thereafter in both treatment groups, and reached prelactation levels at the start of period 2 (Figure 1). Liver TG content did not change during period 2 in both the RES group and the CON group (i.e., feed restriction did not affect liver TG content; Figure 1).

\section{mRNA Abundance of Tumor Necrosis Factor a in Liver}

Within groups, mRNA abundance of tumor necrosis factor $\alpha(\boldsymbol{T N F} \boldsymbol{\alpha})$ did not change over time (Table 2). In wk 3 of period 2, the mRNA abundance of TNF did not differ between RES and CON group.

\section{mRNA Abundance of Hepatic Transporter SLC27A1}

The mRNA abundance of solute carrier family 27 (FA transporter), member 1 (SLC27A1) increased from wk 3 a.p. to a maximum in wk 1 p.p. for RES and CON cows. Compared with wk 1 p.p., the expression of $S L C 27 A 1$ was lowest for both groups in wk 0 of period $2(P<0.05$; Figure 2$)$. Between wk 0 and 3 of period

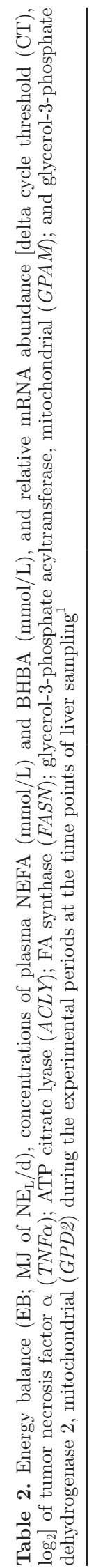




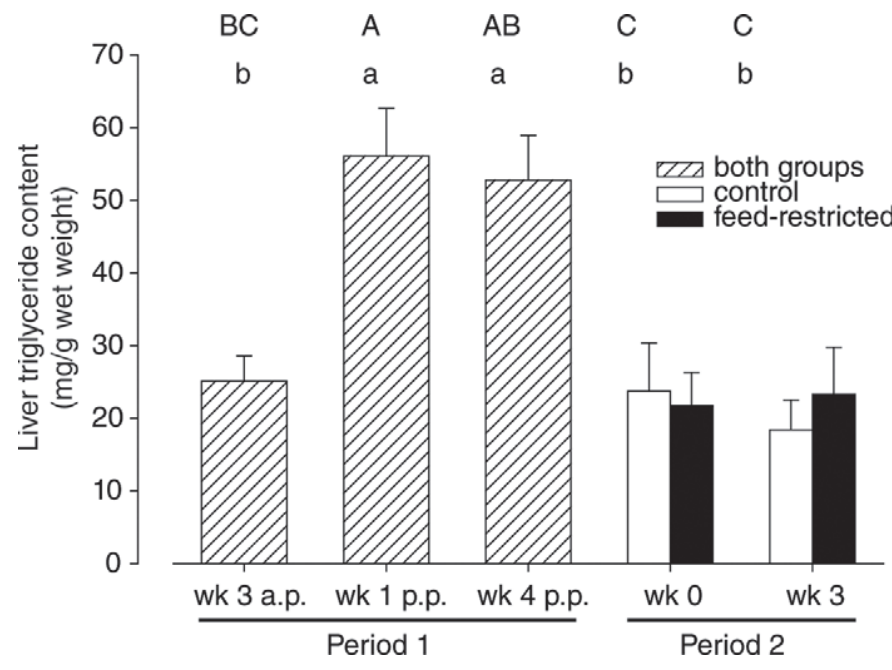

Figure 1. Liver triglyceride content $(\mathrm{mg} / \mathrm{g}$ wet weight) over the time points in cows during experimental period 1 [up to wk 12 postpartum (p.p.)] and period 2 (3 wk of feed restriction). Data are given as mean values \pm SEM. Changes over time within the groups in period 1 [wk 3 antepartum (a.p.), wk 1 and 4 p.p.] and feed restriction beginning at $98 \pm 7$ DIM (period 2, wk 0 and 3) are marked with different letters (A to $\mathrm{C}$ for the control group; $\mathrm{a}$ and $\mathrm{b}$ for the feed-restricted group; $P<0.05)$.

2, no differences were found in SLC27A1 expression for RES and CON groups. For RES cows, the mRNA abundance of SLC27A1 did not differ between wk 1 p.p. (period 1) and wk 3 of period 2. In wk 3 of period 2, RES cows had a higher mRNA abundance of SLC27A1 than CON cows $(P<0.05)$.

\section{mRNA Abundance of Hepatic Enzymes ATP Citrate Lyase; FA Synthase; Acetyl-CoA-Carboxylase a; Glycerol-3-Phosphate Acyltransferase, Mitochondrial; and Glycerol-3-Phosphate Dehydrogenase 2, Mitochondrial}

Neither for CON nor for RES cows, was mRNA abundance of ATP citrate lyase $(\boldsymbol{A} \boldsymbol{C L} \boldsymbol{Y})$ affected over time. No differences were found in wk 3 of period 2 between groups (Table 2).

Compared with period 1 , the mRNA abundance of FA synthase $(\boldsymbol{F A} \boldsymbol{S N})$ was higher in period 2 within groups $(P<0.05$; Table 2$)$. From wk 0 to 3 of period 2 , no differences were found in RES and CON groups for $F A S N$ expression. No differences were found for the hepatic FASN expression between RES and CON cows due to feed restriction in wk 3 of period 2 .

Compared with the other time points, the expression of acetyl-CoA-carboxylase $\alpha(\boldsymbol{A} \boldsymbol{C C})$ was lowest in wk 3 a.p. for the CON and RES groups (Figure 3). No differences in $A C C$ expression were found between wk 0 and 3 of period 2 for both groups. The mRNA abundance of $A C C$ in RES cows between wk 1 p.p. and wk 3 of period 2 did not differ. The expression of $A C C$ in RES cows in wk 3 of period 2 was not different compared with CON cows.

The expression of glycerol-3-phosphate acyltransferase, mitochondrial ( $\boldsymbol{G P A} \boldsymbol{M}$ ) and glycerol-3-phosphate dehydrogenase 2, mitochondrial (GPD2) within the CON and RES groups did not show any differences over time (Table 2). In wk 3 of period 2, the RES group did not differ in mRNA abundance of GPAM and GPD2 compared with the CON group.

\section{Relationships Between Liver TG Content and EB, Metabolites, and Hepatic mRNA Abundances of Lipid Metabolism Parameters}

A significant correlation between liver TG content and EB was only found in wk 1 p.p. $(P<0.05$; Table 3). Plasma metabolites showed only weak correlations with liver TG concentrations. Except $A C C$ in wk 1 p.p. and GPAM in wk 0 (period 2), gene expression data did not show significant relationships for liver TG content (Table 3).

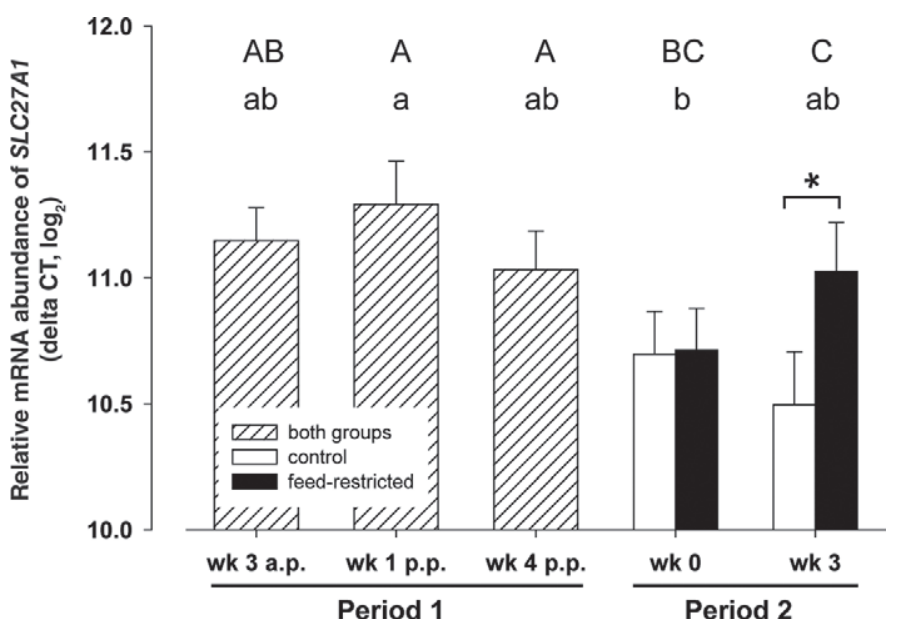

Figure 2. Relative mRNA abundance [delta cycle threshold (CT), $\log _{2}$ ] of solute carrier family 27 (FA transporter), member 1 (SLC27A1) over the time points in cows during experimental period 1 [up to wk 12 postpartum (p.p.)] and period 2 (3 wk of feed restriction). Data are given as mean values \pm SEM. Effects of feed restriction on mRNA abundance for feed-restricted and control cows during period 2 are marked with $*(P<0.05)$. Changes over time within the groups in period 1 [wk 3 antepartum (a.p.), wk 1 and 4 p.p.] and feed restriction beginning at $98 \pm 7$ DIM (period 2, wk 0 and 3 ) are marked with different letters (A to $\mathrm{C}$ for the control group; $\mathrm{a}$ and $\mathrm{b}$ for the feedrestricted group; $P<0.05)$. 


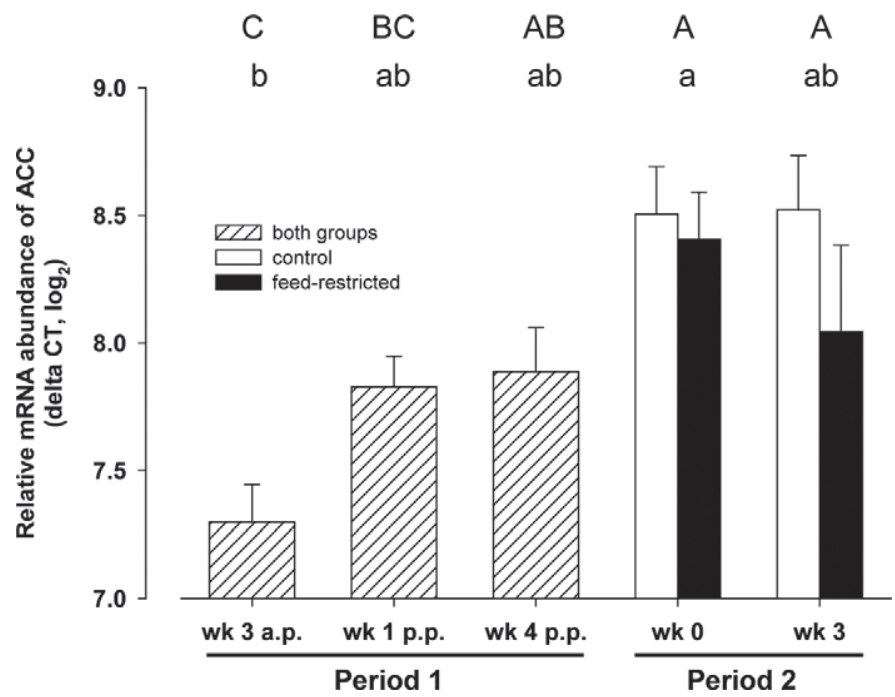

Figure 3. Relative mRNA abundance (delta CT, $\log _{2}$ ) of acetylCoA-carboxylase $\alpha(A C C)$ over the time points in cows during experimental period 1 [up to wk 12 postpartum (p.p.)] and period 2 (3 wk of feed restriction). Data are given as mean values \pm SEM. Changes over time within the groups in period 1 [wk 3 antepartum (a.p.) and wk 1 and 4 p.p.] and feed restriction beginning at $98 \pm 7$ DIM (period 2, wk 0 and 3 ) are marked with different letters (A to $\mathrm{C}$ for the control group; a and b for the feed-restricted group; $P<0.05)$.

\section{DISCUSSION}

\section{Plasma Metabolites and Liver TG Content}

Lipids, mainly TG in adipose tissue, provide high caloric storage of energy compared with protein and glycogen reserves in dairy cows. Energy uptake above the animal's needs results in increasing fat depots. These reserves can be mobilized when the energy requirement exceeds the current supply. Elevated plasma NEFA concentrations indicate a breakdown of adipose tissue (de Boer et al., 1985; Grummer, 1993). In dairy cows, the highest NEFA concentrations in plasma are observed in the first weeks of lactation to compensate for the concomitant NEB (Graber et al., 2010; Gross et al., 2011a). However, in dairy cows, after parturition the mobilization of NEFA is often far beyond the hepatic oxidation capacity (McNamara, 2000). One alternative pathway is the formation of ketone bodies such as BHBA, whose concentration increases consequently in plasma and also in milk and urine. In the first 4 wk p.p., the plasma BHBA concentration was higher compared with its concentration 3 wk a.p. in the present study. Previously, we have shown, in agreement with Doepel et al. (2002), that the elevation of NEFA precedes the peak of BHBA (Gross et al., 2011a). A second alternative for removal of plasma NEFA is their reesterification to TG in the liver, followed by export as constituents of VLDL (Grummer, 1993; Brickner et al., 2009). Based on earlier studies, Brickner et al. (2009) summarized that bovine hepatocytes are inefficient in the VLDL export mechanism and do not increase oxidation or reesterification of NEFA during a NEB. As reviewed by Bobe et al. (2004), the accumulation of hepatic TG decreases clearance rates of hormones (e.g., insulin) as well as of endotoxins in hepatocytes, but also alters sensitivity of tissues toward hormones and even their concentrations. Those authors assumed that secretions of hepatic insulin-like growth factor-I, pancreatic insulin, and thyroid hormones are consequently decreased. Thus, besides decreased gluconeogenesis, lipolysis of adipose tissue is less inhibited and additional NEFA are released that cannot be used efficiently by oxidation. These paradoxical interactions between NEFA, hepatic TG accumulation, and endocrine systems enhance a disadvantageous and accordingly suboptimal regulation of metabolism. In consequence, the excessive infiltration of TG in the liver reduces animal health and productivity and promotes their susceptibility to metabolic and infectious diseases (Bobe et al., 2004). In their review, Bobe et al. (2004) classified fatty liver in dairy cows due to their TG content into 4 categories: normal, mild, moderate, and a severe form. Simultaneously with the highest concentration of NEFA, dairy cows in the present study had the highest liver TG content in wk 1 p.p., whose value can be attributed to the classification "moderate fatty liver" according to Bobe et al. (2004). Even in wk 4 p.p., the liver fat content was similarly high, although the NEB improved and plasma NEFA concentration decreased. In the first weeks after parturition, up to $40 \%$ of dairy cows suffer from a moderate fatty liver, whereas only 5 to $10 \%$ develop a severe form of liver steatosis (Bobe et al., 2004). de Boer et al. (1985) and Mazur et al. (1988) showed high associations of fatty liver with plasma BHBA and NEFA concentrations. Whereas Bertics et al. (1992) showed that fatty liver developed already before parturition, Vazquez-Añon et al. (1994) located the beginning of the onset of hepatic TG infiltration at the acute NEFA increase directly after parturition. After we did not find any relationship for liver TG content and plasma NEFA concentration in early lactation, we assume that susceptibility to development of fatty liver is not only related to high plasma NEFA levels. Moreover, the simultaneous hepatic export of TG by VLDL seems to be the main regulator of TG accumulation in the liver.

The question came up if dairy cows in the present study would respond similarly in developing a fatty liver when they experience a second NEB later on in lactation that is comparable in its degree to the first NEB occurring directly after parturition. Although the extent of the NEB induced by feed restriction 
Table 3. Regression analysis parameters for the relationship between liver triglyceride concentration as predictor variable and different parameters during the experimental periods at the time points of liver sampling

\begin{tabular}{|c|c|c|c|c|c|c|c|}
\hline \multirow[b]{2}{*}{ Variable $^{1}$} & \multicolumn{3}{|c|}{ Period $1^{2}$} & \multicolumn{4}{|c|}{ Period $2^{3}$} \\
\hline & wk 3 a.p. & wk 1 p.p. & wk 4 p.p. & $\mathrm{CON}$ & RES & $\mathrm{CON}$ & RES \\
\hline \multicolumn{8}{|c|}{$\overline{\mathrm{EB}\left(\mathrm{MJ} \text { of } \mathrm{NE}_{\mathrm{L}} / \mathrm{d}\right)}$} \\
\hline Intercept & 28.18 & 27.35 & 43.58 & 23.72 & 24.05 & 18.42 & 37.98 \\
\hline Slope & -0.11 & -0.66 & -0.37 & 0.01 & -0.25 & -0.00 & 0.24 \\
\hline \multicolumn{8}{|c|}{ Concentration $(\mathrm{mmol} / \mathrm{L})$} \\
\hline \multicolumn{8}{|c|}{ NEFA } \\
\hline Intercept & 15.35 & 46.55 & 41.99 & 16.70 & -1.09 & 20.37 & 11.46 \\
\hline Slope & 27.06 & 14.01 & 24.37 & 55.71 & 195.85 & -22.55 & 66.75 \\
\hline $\mathrm{R}^{2}$ & 0.08 & 0.04 & 0.05 & 0.04 & 0.19 & 0.00 & 0.07 \\
\hline$P$-value & 0.08 & 0.26 & 0.24 & 0.36 & 0.04 & 0.84 & 0.24 \\
\hline \multicolumn{8}{|l|}{ BHBA } \\
\hline \multicolumn{8}{|c|}{$T N F \alpha$} \\
\hline Intercept & 46.09 & 33.13 & -6.38 & -121.26 & 91.96 & 94.58 & 85.81 \\
\hline Slope & -2.23 & 2.33 & 6.07 & 14.16 & -6.75 & -7.54 & -5.96 \\
\hline $\mathrm{R}^{2}$ & 0.01 & 0.00 & 0.03 & 0.15 & 0.08 & 0.17 & 0.02 \\
\hline$P$-value & 0.59 & 0.80 & 0.39 & 0.07 & 0.19 & 0.08 & 0.58 \\
\hline \multicolumn{8}{|l|}{$A C L Y$} \\
\hline Intercept & 127.35 & 254.99 & 56.33 & 18.86 & 124.49 & 78.95 & 374.10 \\
\hline Slope & -7.71 & -14.38 & -0.17 & 0.42 & -7.78 & -4.45 & -26.09 \\
\hline $\mathrm{R}^{2}$ & 0.08 & 0.04 & 0.00 & 0.00 & 0.06 & 0.04 & 0.56 \\
\hline$P$-value & 0.11 & 0.27 & 0.98 & 0.96 & 0.26 & 0.43 & $<0.001$ \\
\hline \multicolumn{8}{|l|}{$F A S N$} \\
\hline Intercept & 71.54 & 198.31 & 45.03 & 26.56 & 15.81 & 61.56 & 75.94 \\
\hline Slope & -3.96 & -11.21 & 0.79 & -0.16 & 0.44 & -3.20 & -4.30 \\
\hline $\mathrm{R}^{2}$ & 0.10 & 0.07 & 0.00 & 0.00 & 0.00 & 0.04 & 0.09 \\
\hline \multicolumn{8}{|l|}{$G P A M$} \\
\hline $\mathrm{R}^{2}$ & 0.04 & 0.03 & 0.04 & 0.24 & 0.09 & 0.05 & 0.11 \\
\hline$P$-value & 0.27 & 0.34 & 0.28 & 0.02 & 0.16 & 0.34 & 0.18 \\
\hline \multicolumn{8}{|l|}{ GPD2 } \\
\hline Intercept & 32.43 & 153.94 & 31.97 & -71.47 & -35.35 & 13.70 & -77.55 \\
\hline Slope & -1.01 & -10.42 & 2.51 & 10.52 & 6.15 & 0.54 & 10.98 \\
\hline $\mathrm{R}^{2}$ & 0.00 & 0.05 & 0.01 & 0.08 & 0.07 & 0.00 & 0.06 \\
\hline$P$-value & 0.75 & 0.24 & 0.66 & 0.19 & 0.24 & 0.90 & 0.34 \\
\hline \multicolumn{8}{|l|}{ SLC27A1 } \\
\hline Intercept & -10.17 & -117.39 & 12.85 & -57.92 & 5.47 & -3.63 & 43.23 \\
\hline Slope & 3.05 & 15.54 & 3.90 & 7.71 & 1.52 & 2.13 & -2.30 \\
\hline $\mathrm{R}^{2}$ & 0.02 & 0.09 & 0.01 & 0.04 & 0.00 & 0.01 & 0.01 \\
\hline$P$-value & 0.46 & 0.11 & 0.55 & 0.36 & 0.80 & 0.64 & 0.66 \\
\hline
\end{tabular}

${ }^{1} \mathrm{~EB}=$ energy balance; $T N F \alpha=$ tumor necrosis factor $\alpha ; A C L Y=\mathrm{ATP}$ citrate lyase; $F A S N=\mathrm{FA}$ synthase; $A C C=$ acetyl-CoA-carboxylase $\alpha$; $G P A M=$ glycerol-3-phosphate acyltransferase, mitochondrial; GPD2 = glycerol-3-phosphate dehydrogenase 2, mitochondrial; SLC27A1 = solute carrier family 27 (FA transporter), member 1.

${ }^{2}$ a.p. = antepartum; p.p. = postpartum.

${ }^{3} \mathrm{CON}=$ control; RES $=$ feed restricted. 
in mid lactation was even higher compared with the NEB in early lactation, plasma NEFA concentration was elevated only to a smaller extent, whereas BHBA concentration did not differ between groups during feed restriction (Gross et al., 2011a). Nevertheless, cows mobilized body reserves to a comparable extent to early lactation, as indicated by a decrease in BCS and back fat thickness (Gross et al., 2011a). In the later lactational stage, dairy cows seem to react less intensely to a NEB regarding NEFA and BHBA concentration, as shown in feed-restricted mid-lactation dairy cows (Carlson et al., 2006). The lower BHBA concentrations in period 2 can be explained as a consequence of the lower plasma NEFA levels. Moreover, feed restriction did not lead to development of fatty liver in the present study either. Emery et al. (1992) showed a proportional hepatic uptake of NEFA to its plasma concentration. Therefore, NEFA did not seem to overload hepatic $\beta$-oxidation and VLDL export capacity in mid lactation, as they were only increased marginally by feed restriction. However, feed of poor quality (e.g., silage with high butyrate concentration) increased the incidence of fatty liver as BHBA formation was elevated and feed intake was decreased in dairy cows (Stöber and Scholz, 1991; reviewed by Bobe et al., 2004). Whenever feed intake is depressed, the occurrence of a NEB additionally results in mobilization and release of NEFA that, in turn, promote TG accumulation in the liver of periparturient dairy cows, independent of stage of lactation (Katoh, 2002). However, data on fatty liver in mid- and late-lactating dairy cows can be rarely found in the literature. Contrary to our findings, feed-restricted dairy cows (around 132 DIM) in the study of Carlson et al. (2006) had an increase in liver TG content. Those authors found that feed restriction did not affect the rate of palmitate oxidation or the proportion of palmitate oxidized. Furthermore, the rate of total $\beta$-oxidation increased from the beginning of lactation onwards (Grum et al., 2002). Along with the low increase in plasma NEFA concentration during feed restriction in the present study, the higher capability for their oxidation at the onset of NEB induction at 100 DIM gives a conclusive explanation for the unchanged liver TG concentration.

\section{Gene Expression of Parameters and Enzymes Related to Lipid Metabolism in the Liver}

Although plasma metabolites and liver TG concentration followed numerous previous findings dealing with periparturient dairy cows, hepatic expression of TNFQ was not affected by treatment or stage of lactation in the present study, indicating no inflammatory challenge. In contrast, Loor et al. (2005) found positive correlations between the expression of mRNA encoding for the proinflammatory cytokine TNFa and lipomobilization and oxidation. In the present study, no significant relationships were observed for plasma NEFA and BHBA with $T N F \alpha$ expression in the liver (data not shown). Furthermore, Loor et al. (2005) postulated a causal link between hepatic inflammation and TG accumulation, which could not be verified in the present study.

The solute carrier family 27 (FA transporter), member 1, also known as FATP1, mediates the translocation of long-chain FA across plasma membranes. Although Ordovás et al. (2006) found only very low expression levels of SLC27A1 in the bovine liver and Gimeno (2007) attested hepatic FATP1 absence or no relevance in FA incorporation, this transporter nevertheless seems to be of importance in the present study. Mean expression of $S L C 27 A 1$ was highest in wk 1 p.p. in the present study along with highest plasma NEFA and liver TG concentration, in agreement with Schlegel et al. (2012), and interestingly elevated for feed-restricted cows compared with control cows. To our knowledge, this paper shows distinct results on expression of SLC27A1 in the bovine liver during feed restriction in mid lactation for the first time. In contrast, SCL27A2 (FATP2) is highly expressed in the liver (Gimeno, 2007) and might be assumed to act in the same way as FATP1; SLC27A2 was upregulated during feed restriction in early lactating dairy cows to cope with increased NEFA influx (Loor et al., 2007). These findings would support the mRNA expression pattern of SLC27A1 in the present study during the NEB both early lactation and feed restriction, indicating an enhanced uptake of plasma NEFA into the liver.

In the present study, liver TG content was highest in wk 1 p.p. Previous studies (e.g., Bertics et al., 1992) found that fatty liver developed already before parturition. Besides the prepartum increase in NEFA concentration, also changes in regulatory mechanisms of FA oxidation and lipogenesis in hepatocytes must take place during the periparturient period. However, the sampling schedule of the present study did not allow us to determine the initiation of fatty liver development. The GPAM gene encodes for the glycerol-3-phosphateacyltransferase (GPAT), an enzyme that catalyzes the initial step in glycerolipid synthesis and, therefore, plays an important role in the regulation of cellular TG concentrations. Whereas in the present study, mRNA abundance of GPAM was not significantly altered during the entire experiment, previous studies (Loor et al., 2006; Graber et al., 2010) found a downregulation of GPAM in early lactation, which supports channeling of NEFA toward FA oxidation. Because GPAM is not limiting for hepatic TG accumulation (Loor et al., 2006), 
the development of fatty liver in early lactation can be explained despite an unchanged expression pattern of GPAM in the present study. Graber et al. (2010) showed for GPD2 (involved in the glycerol-3-phosphate shuttle for regeneration of $\mathrm{NAD}^{+}$) a decrease in its expression in wk 4 p.p. compared with wk 3 a.p. Those authors also suggested the orientation toward increased NEFA oxidation as an interpretation for their findings. In the present study, neither in early lactation nor during feed restriction did GPD2 change, which might also indicate that expression might be not limiting for accomplishing its task in lipid metabolism.

Up to wk 4 p.p. in the present study, mRNA abundances of FASN and $A C C$ were lower compared with the feed-restriction period starting in wk 14 p.p. Although these findings for $A C C$ apply only numerically, along with the expression pattern of FASN, they are in agreement with the results of Graber et al. (2010), who performed liver sampling at predominantly identical time points. Reduced expression of FASN and $A C C$ during the peripartal period in dairy cows mirrors reduced lipogenic activity in the liver (Graber et al., 2010), which was confirmed earlier by lowered activities of these enzymes postpartum (Murondoti et al., 2004). Thus, during the NEB induced by feed restriction at around 100 DIM, synthesis of FA formed by acetyl-CoA and malonyl-CoA seems to be upregulated compared with the NEB after parturition in the present study. In contrast, feed restriction performed directly after parturition to induce ketosis (Dann et al., 2005) was associated with a downregulation of FASN and ACC (Loor et al., 2007). Consequently, not a NEB per se, but also stage of lactation affects de novo synthesis of FA in the liver.

The regulation of ACC activity by feedback via NEFA and their CoA-esters was reported earlier (e.g., Wolfrum and Spener, 2000). As reviewed by those authors, however, studies relating to control of FASN and ACLY activity remain contradictory. The mRNA abundance of $A C L Y$ was not affected by time or treatment in the present study as well as previously reported by van Dorland et al. (2009). Hanson and Ballard (1967) approved the appearance of only moderate ACLY activity in the bovine liver, as reflected by the lack of changes in its mRNA expression in recent studies. On the other hand, Graber et al. (2010) supposed the involvement of $A C L Y$ expression in the adaptation process of periparturient dairy cows.

\section{CONCLUSIONS}

In the present study, changes in lipid metabolism were observed at different levels and sites of metabolism. Whereas the postpartum NEB resulted in a cer- tain degree of fatty liver, the NEB induced by feed restriction did not lead to an increased hepatic TG accumulation in mid-lactation cows. Expression of genes related to lipid metabolism did not show a consistent pattern during the study. However, hepatic uptake of mobilized FA for oxidation seemed to be enhanced during feed restriction and of comparable extent to early lactation. Therefore, the homeorhetic adaptations during the periparturient period trigger excessive responses in metabolism, which the liver and other tissues have to cope with. In contrast, during homeostatic control of endocrine and metabolic systems after established lactation, as during the period of feed restriction in the present study, organs are well adapted to metabolic and environmental changes.

\section{ACKNOWLEDGMENTS}

The authors thank Yolande Zbinden and Claudine Morel (Veterinary Physiology, University of Bern, Bern, Switzerland) for the blood plasma and gene expression analyses.

\section{REFERENCES}

Bauman, D. E., and W. B. Currie. 1980. Partitioning of nutrients during pregnancy and lactation: A review of mechanisms involving homeostasis homeorhesis. J. Dairy Sci. 63:1514-1529.

Bertics, S. J., R. R. Grummer, C. Cadorniga-Valino, and E. E. Stoddard. 1992. Effect of prepartum dry matter intake on liver triglyceride concentration and early lactation. J. Dairy Sci. 75:19141922.

Bobe, G., J. W. Young, and D. C. Beitz. 2004. Invited review: Pathology, etiology, prevention and treatment of fatty liver in dairy cows. J. Dairy Sci. 87:3105-3124.

Brickner, A. E., J. A. A. Pires, T. F. Gressley, and R. R. Grummer. 2009. Effects of abomasal lipid infusion on liver triglyceride accumulation and adipose lipolysis during fatty liver induction in dairy cows. J. Dairy Sci. 92:4954-4961.

Carlson, D. B., N. B. Litherland, H. M. Dann, J. C. Woodworth, and J. K. Drackley. 2006. Metabolic effects of abomasal L-carnitine infusion and feed restriction in lactating Holstein cows. J. Dairy Sci. 89:4819-4834.

Dann, H. M., D. E. Morin, G. A. Bollero, M. R. Murphy, and J. K. Drackley. 2005. Prepartum intake, postpartum induction of ketosis, and periparturient disorders affect the metabolic status of dairy cows. J. Dairy Sci. 88:3249-3264.

de Boer, G., A. Trenkle, and J. W. Young. 1985. Glucagon, insulin, growth hormone, and some blood metabolites during energy restriction ketonemia of lactating cows. J. Dairy Sci. 68:326-337.

Doepel, L., H. Lapierre, and J. J. Kennelly. 2002. Peripartum performance and metabolism of dairy cows in response to prepartum energy and protein intake. J. Dairy Sci. 85:2315-2334.

Drackley, J. K., S. S. Donkin, and C. K. Reynolds. 2006. Major advances in fundamental dairy cattle nutrition. J. Dairy Sci. 89:1324-1336.

Emery, R. S., J. S. Liesman, and T. H. Herdt. 1992. Metabolism of long chain fatty acids by ruminant liver. J. Nutr. 122(Suppl.):832-837.

Gimeno, R. E. 2007. Fatty acid transport proteins. Curr. Opin. Lipidol. 18:271-276.

Graber, M., S. Kohler, T. Kaufmann, M. G. Doherr, R. M. Bruckmaier, and H. A. van Dorland. 2010. A field study on characteristics and diversity of gene expression in the liver of dairy cows during the transition period. J. Dairy Sci. 93:5200-5215. 
Gross, J., H. A. van Dorland, R. M. Bruckmaier, and F. J. Schwarz. 2011a. Performance and metabolic profile of dairy cows during a lactational and deliberately induced negative energy balance by feed restriction with subsequent realimentation. J. Dairy Sci. 94:1820-1830.

Gross, J., H. A. van Dorland, F. J. Schwarz, and R. M. Bruckmaier. 2011b. Endocrine changes and liver mRNA abundance of somatotropic axis and insulin system constituents during negative energy balance at different stages of lactation in dairy cows. J. Dairy Sci. 94:3484-3494.

Grum, D. E., J. K. Drackley, and J. H. Clark. 2002. Fatty acid metabolism in liver of dairy cows fed supplemental fat and nicotinic acid during an entire lactation. J. Dairy Sci. 85:3026-3034.

Grummer, R. R. 1993. Etiology of lipid-related metabolic disorders in periparturient dairy cows. J. Dairy Sci. 76:3882-3896.

Hanson, R. W., and F. J. Ballard. 1967. The relative significance of acetate and glucose as precursors for lipid synthesis in liver and adipose tissue from ruminants. Biochem. J. 105:529-536.

Katoh, N. 2002. Relevance of apolipoproteins in the development of fatty liver and fatty liver-related peripartum diseases in dairy cows. J. Vet. Med. Sci. 64:293-307.

Loor, J. J., H. M. Dann, R. E. Everts, R. Oliveira, C. A. Green, N. A. Janovick-Guretzky, N. Litherland, S. L. Rodriguez-Zas, H. A. Lewin, and J. K. Drackley. 2006. Plane of nutrition prepartum alters hepatic gene expression and function in dairy cows as assessed by longitudinal transcript and metabolic profiling. Physiol. Genomics 27:29-41.

Loor, J. J., H. M. Dann, R. E. Everts, R. Oliveira, C. A. Green, N. A. Janovick-Guretzky, S. L. Rodriguez-Zas, H. A. Lewin, and J. K. Drackley. 2005. Temporal gene expression profiling of liver from periparturient dairy cows reveals complex adaptive mechanisms in hepatic function. Physiol. Genomics 23:217-226.

Loor, J. J., R. E. Everts, M. Bionaz, H. M. Dann, D. E. Morin, R. Oliveira, S. L. Rodriguez-Zas, J. K. Drackley, and H. A. Lewin. 2007. Nutrition-induced ketosis alters metabolic and signaling gene networks in liver of periparturient dairy cows. Physiol. Genomics 32:105-116.

Mazur, A., S. Bazin, and Y. Rayssiguier. 1988. Study of hepatic steatosis at the start of lactation in dairy cows consuming grass silage. Reprod. Nutr. Dev. 28:171-172.
McNamara, J. P. 2000. Integrating genotype and nutrition on utilization of body reserves during lactation of dairy cattle. Pages 353-370 in Symposium on Ruminant Physiology. P. B. Cronje, ed. CAB Int. London, UK.

Murondoti, A., R. Jorritsma, A. C. Beynen, T. Wensing, and M. J. H. Geelen. 2004. Unrestricted feed intake during the dry period impairs the postpartum oxidation and synthesis of fatty acids in the liver of dairy cows. J. Dairy Sci. 87:672-679.

Ordovás, L., R. Roy, P. Zaragoza, and C. Rodellar. 2006. Structural and functional characterization of the bovine solute carrier family 27 member 1 (SLC27A1) gene. Cytogenet. Genome Res. 115:115122

Rukkwamsuk, T., T. A. Kruip, and T. Wensing. 1999. Relationship between overfeeding and overconditioning in the dry period and the problems of high producing dairy cows during the postparturient period. Vet. Q. 21:71-77.

Schlegel, G., J. Keller, F. Hirche, S. Geißler, F. J. Schwarz, R. Ringseis, G. I. Stangl, and K. Eder. 2012. Expression of genes involved in hepatic carnitine synthesis and uptake in dairy cows in the transition period and at different stages of lactation. BMC Vet. Res. 8:28.

Stöber, M., and H. Scholz. 1991. Treatment of dairy cow for lipomobilization syndrome. Monatsh. Veterinärmed. 46:563-566. (In German; abstract in English).

van Dorland, H. A., S. Richter, I. Morel, M. G. Doherr, N. Castro, and R. M. Bruckmaier. 2009. Variation in hepatic regulation of metabolism during the dry period and in early lactation in dairy cows. J. Dairy Sci. 92:1924-1940.

Vazquez-Añon, M., S. Bertics, M. Luck, R. R. Grummer, and J. Pinheiro. 1994. Peripartum liver triglyceride and plasma metabolites in dairy cows. J. Dairy Sci. 77:1521-1528.

Veenhuizen, J. J., J. K. Drackley, M. J. Richard, T. P. Sanderson, L. D. Miller, and J. W. Young. 1991. Metabolic changes in blood and liver during development and early treatment of experimental fatty liver and ketosis in cows. J. Dairy Sci. 74:4238-4253.

Wolfrum, C., and F. Spener. 2000. Fatty acids as regulators of lipid metabolism. Eur. J. Lipid Sci. Technol. 102:746-762. 